\title{
The Chilean Experience with a National Formulary in the 1960s
}

\author{
Ramón Valdivieso
}

In 1969 a decree of the Ministry of Health, which incorporated a list of essential drugs identified by their generic names, reached the statute book in Chile. Much technical work and political preparation had preceded this event. The decree had two main purposes. It was intended to rationalise the use of pharmaceutical products and to benefit the consumers, including the health service, by reducing the cost of drugs. This article deals with the historical background to this development, discusses some of the problems in bringing it about, and briefly examines the more recent fate of this system created earlier than many in the developing world.

\section{Historical Background}

Before 1924, health care in Chile was provided by several organisations, the most important being the charitable Beneficiencia. It managed almost all the hospitals and health services which were the responsibility of local councils and the government's Direccion General de Sanidad.

In 1924, Ezequiel Gonzalez Cortes, a distinguished professor of medicine who was also a Senator, promoted workers' health protection legislation inspired by the German Krankenkasse. This led to the approval of the law on compulsory workers insurance, the Seguro Obrero Obligatorio (SOO). Together with the corresponding fund (the Caja de Seguro Obrero or Manual Workers Fund) it formed the basis of an organised health system for manual workers and the beginning of social security in Chile [Valdivieso and Juricic 1970].

The Manual Workers Fund organised its own outpatient services through health centres and by means of domiciliary visits. For hospital treatment it arranged a covenant with the Beneficiencia, which enabled the Fund to keep costs down. Those affiliated to the Manual Workers Fund acquired the right to curative and preventive health care for themselves and their families, as well as illness and retirement benefits. Doctors had absolute freedom in the drugs they prescribed, and the patients received free prescriptions. It soon became evident that the procedure was being abused. The Fund's management board sought outside advice, and it was proposed that a list be drawn up of those drugs which were used most frequently and could be produced locally on an industrial basis. The outcome was the Arsenal Farmacológico of the SOO. Its main purpose was to eliminate, wherever possible, obsolete formulae for extemporaneous preparations. At this time - the end of the $1930 \mathrm{~s}$ - therapy was still mainly symptomatic, and as there were relatively few drugs that were pharmacologically active, many placebos were being used.

The next important step was the purchase by the Manual Workers Fund of a pharmaceutical company, the Laboratorio Chile. From then onwards this company concentrated on producing the drugs from the Arsenal Farmacológico of the SOO.

These developments constituted the beginnings of a partial socialisation of health care in Chile. There can be no doubt that the results were satisfactory for the Manual Workers Fund: expenditure was controlled and there was no deterioration in the medical services provided.

During the 1940s and 1950s came the discovery of a wide range of new pharmaceuticals, notably the antibacterial drugs. These were spectacularly effective in controlling diseases that had been crippling and fatal before, but they also often caused adverse reactions in patients. Self-medication increased, and this was one of the factors that brought about a rise in the unjustified use of drugs. As a result, departments of pharmacological surveillance were set up in many hospitals in Chile.

In 1952, the Beneficiencia with its hospitals, the medical services of the Manual Workers Fund, the municipal health services, and the Bacteriological Institute were all incorporated into one organisation 
dependent on the Ministry of Health, the servicio nacional de salud (SNS). The SNS took responsibility for preventive health care for the country's entire population. It was also to provide curative services (including rehabilitation) for all manual workers and peasants and their families. These represented together some 70 per cent of the Chilean population. The SNS came to administer 86 per cent of the country's hospital beds, and employed - on a full- or part-time basis -89 per cent of the country's medical doctors.

In 1961, as pharmaceuticals began to emerge as an issue, the SNS decided to replace a considerable number of patented pharmaceutical products used in its hospitals by the equivalent generic drugs. The resources saved as a result turned out to be very considerable indeed.

\section{The Ministry of Health Intervenes}

At the beginning of 1965 the Minister of Health in the government of the newly elected President Frei, outlined for the Senate Health Commission the government's health policy proposals for its six year period of office. These included the decision to bring about substantial changes in the systems of supply and marketing of pharmaceutical products. It was on this occasion that the idea of the Formulario Nacional de Medicamentos, the National Formulary (NF), was first mooted.

The pharmaceutical problem in Chile had various roots. Some of these were specific to the country and its economic situation, and others were related to the commercial practices of the transnational pharmaceutical industry. Price rises of pharmaceutical products had always had social repercussions in the country similar to those for basic goods like bread or sugar - whether these resulted from inflation, real increases in costs, or a combination of both. The government concluded that it was its responsibility to control the costs of pharmaceuticals.

A price control policy had already been in operation for a number of years. Prices were fixed in relation to production costs - as declared, or sometimes as established after an investigation. However, it soon became obvious that for this type of product the procedure was purely fictional. Reliable data on the costs of pharmaceutical products were just not available, the more so as the main production units of this industry in Chile were subsidiaries of multinational companies, whose prices for basic drugs and certain other inputs were set arbitrarily by their head offices. As for the national companies which produced finished drugs, these frequently resorted to double invoicing, so that it was equally difficult to assess real production costs. Moreover, the use of brand names and patents nullified the potentially beneficial effect of the interplay of supply and demand on market prices. With the operation of monopolistic and oligopolistic forces, price setting had become discretionary.

Problems such as these were also brought out during the hearings on the pharmaceutical industry of the United States Senate Subcommittee on Monopolies, under the chairmanship of Senator Kefauver, which focused its attention on the peculiar conditions characterising production and trade in that industry in relation to existing anti-trust legislation in the United States. Witnesses before the Subcommittee emphasised the high rate of profit in the industry, given the lack of effective price competition brought about by patent protection and vast promotional expenditures for proprietary drugs, especially where generic alternatives were available on the market. These hearings occurred when the formulation of a pharmaceutical policy in Chile was already well advanced. They did, however, play an important role in the development of events, as decision makers in Chile became convinced that the implementation of such a policy was indeed a matter of urgency. ${ }^{1}$

\section{The National Formulary Bill}

Mention has already been made of the benefit to the SNS of replacing brand name products by generic drugs wherever possible in its pharmacies. Instituting a list of generic drugs greatly reduced hospital expenditure, but other measures were needed to deal with the problem outside the hospitals, especially because non-hospital expenditure accounted at that time for more than four-fifths of the national expenditure on drugs. A survey carried out in Santiago in 1964 had shown that on average over 40 per cent of personal health expenditure went on pharmaceutical products. The proportion was even higher among the poorer sections of the population and rose to 75 per cent for the lowest income bracket [Diaz 1966]. So in December 1965 the Ministry of Health installed a Commission, made up of senior academics from relevant departments of the medical school of the University of Chile and representatives of the various health professional associations and of the public health services, to advise on a national formulary.

The Minister of Health gave the Commission, at its opening session, the following terms of reference:

After an exhaustive study of the drug problem, this Ministry is convinced that the present system of supplying the country with drugs needs to be

'The report of the hearings can be consulted in United States, Senate, 1968. 
urgently modified. Their use needs to be rationalised, in order to ensure scientific efficacy and economic benefits. Not all pharmaceutical products on the market have a recognised therapeutic value, and it is well known that many of them have none at all. The number of genuine ethical drugs is vastly lower than the total supplied by the pharmaceutical industry to the market ...

[There are as well, too many] combinations of drugs that can hardly be justified, or that are even absolutely useless. Yet their use increases total health expenditure. The Commission will have as its task to recommend a list of essential indispensable - drugs, which are needed in an efficient therapy that accords with the present state of medical knowledge. A brief explanatory statement is to accompany each group of drugs, in order to provide better information for the medical profession.

[Ministério de Salud, 1966]

The Commission was given permanent status, so that the national formulary could be updated from time to time, in the light of scientific advances.

The institutionalisation of the NF Commission as a permanent body had a number of important consequences. In conjunction with the authorities of the SNS it was given the role of deciding on the licensing of all new pharmaceutical products to be introduced in the country. It was thereby in a position to influence the rationalisation of drug use. Perhaps even more important, however, was the standing of the Commission's members in the scientific community and the participation of the Chilean Medical Association (the Colégio Medico de Chile) in its deliberations. This meant that the pharmacological and therapeutic information on each group of drugs published in successive editions of the NF had a chance of being taken seriously by physicians throughout the health sector. In this way a counterweight might be provided to the commercial publicity for the proprietary products in the private sector. So there was a fair chance that the NF drugs would also find their way into general use as a result of new prescribing patterns. A simple list of generics could have been imposed upon the hospitals by administrative fiat of the Ministry of Health. However, the chance of influencing the wider pattern of drug use in the country would have been lost.

The criterion for inclusion in the NF was that a product should 'have a universally recognised therapeutic value' [Ministério de Salud 1969:35]. Not all the excluded drugs were seen as lacking therapeutic effectiveness; some were left out because they were broadly interchangeable with drugs that were included but which were regarded as having the balance of advantages.

In summary, the NF was part of a policy that at tempted to rationalise the use of drugs, to lower their costs without allowing deterioration in the quality, and to facilitate their supply. It was given legal sanction in January 1969 and the first edition was published shortly afterwards.

\section{Upgrading of the Laboratorio Chile}

During the two and a half years it took to compile the $\mathrm{NF}$, measures were taken to modernise the equipment of Laboratorio Chile. It has already been mentioned that this enterprise had been acquired by the Manual Workers Fund many years earlier. Now, under the impulse of the Ministry of Health, its share capital was considerably increased, the capital being provided by social security institutions and the SNS. This facilitated its modernisation and enlargement. Important in this respect was the setting up of an independent department for quality control, appropriately staffed and equipped for this task. In parallel with this unit for producing pharmaceutical products another public enterprise, the Instituto Bacteriológico (today incorporated in Laboratorio Chile), was used to manufacture common vaccines and antitoxins, as well as penicillin and chloramphenicol. Thus Chile built up its stated-owned production capacity for pharmaceuticals.

Laboratorio Chile entered a field with a large number of established enterprises: well over 50 pharmaceutical producers. Although the majority of these were nationally owned, two thirds of the 25 largest producers were subsidiaries of transnational corporations (TNCs). About half of the latter were North American, the rest were European. Bet ween them they produced almost all the drugs for domestic consumption in Chile, with the TNC subsidiaries importing the active ingredients from their parent companies and the national firms doing so from different producers in Western and Eastern Europe. Only very few drugs were imported as finished products because of their special technical characteristics or production costs (for example insulin, gamma-globulin, poliomyelitis vaccine, and anticancer drugs). In spite of this situation, Laboratorio Chile eventually established itself as a leading enterprise, both in terms of production and of domestic sales. It started producing the first batch of about 20 products listed in the NF after the latter's legal approval. 


\section{Private Industry Confronts the National Formulary}

Once the government's pharmaceutical policy had been given wide publicity in the country and was even beginning to be discussed abroad [Business International 1968], the Ministry of Health called a meeting of all the pharmaceutical firms operating in the country, both national and multinational. Representatives of almost all firms attended this meeting. It was the occasion at which they were officially informed of the new policy, whose implementation was about to start with the delivery of the first NF products to the country's pharmacies.

The reasons for proceeding with the new policy were explained. It was pointed out that one of its important aims was to safeguard the people's health, but that economic considerations were no less central. The policy was intended to provide economic protection for the consumers, particularly those with low incomes, and for the health care services whose budgets were greatly affected by the rising cost of drugs. These objectives, it was stressed, could not be achieved if the public sector did not have its own productive capacity; hence Laboratorio Chile had been provided with considerable resources which placed it in a privileged position. It was now capable of manufacturing products of the highest quality, and its capacity could be rapidly expanded to meet all needs. Nevertheless, so it was emphasised during the meeting, the Ministry wished to give private industry the opportunity of collaborating in this highly significant project. This collaboration would also be in the government's interest, given that it aimed to see all the drugs included in the NF produced, as soon as possible, in sufficient volume to provide a satisfactory domestic supply.

It was made very clear that all public sector health care services, and not only hospitals, would henceforth be supplied exclusively with NF drugs. Any private sector firm prepared to participate in the production of one or more NF generic products would also be allowed to market its own equivalent proprietary brand without being subjected to price controls; this would be on the understanding that the company would produce the generic brand concerned according to NF specifications, at an agreed level of output, and in competition with Laboratorio Chile or any other pharmaceutical enterprise. For example: were Roche to agree to produce NF chlordiazepoxide capsules $10 \mathrm{mg}$, it would be at liberty to market its Librium capsules $10 \mathrm{mg}$ at its own price.

The reaction of those present at the meeting was evasive. The TNCs were convinced that the government was heading for failure. On its part, the government was convinced that it could only put the TNCs under pressure in the battle over drug prices by providing the essential drugs competitively as generics, backed up by the NF.

As the first NF products were becoming available in the country's pharmacies, a supportive leading article appeared in the official bulletin of the Chilean Medical Association, whose representatives had participated in the Commission that elaborated the NF. It stated: 'This represents a positive step forward in the country's public health. It has momentous significance, as it helps simplify prescribing and substantially diminishes the cost of drugs - which directly benefits the needy classes' [Colegio Médico de Chile 1969].

The support of the Medical Association was seen, from the start, as crucial to the success of the policy. Its own channels of communication with the country's physicians could become for them the most effective and important source of drug information, giving them sober, scientific, and independent facts on the prescribing practices likely to be of greatest benefit to their patients. Generic products could thus be promoted, and the all-pervasive publicity for proprietary brands neutralised. In addition, as most physicians worked part time in the public sector, they would have a chance to familiarise themselves with the management of generic products, as these would henceforth be compulsory there.

Towards the end of 1969 , a second batch of 30 further NF products were added to those already on the market. Table 1 lists some examples to give an idea of the economic importance of the whole venture for the consumer.

\section{The International Health Organisations Ignore the Experience}

In July 1969 the World Health Assembly met in Boston, USA. In one of the plenary sessions the Chilean delegate outlined the country's pharmaceutical policy and its achievements to date. A detailed analysis was presented, and emphasis was placed on the central aim of reducing the cost of those drugs defined as essential, in order to make an impact on the expenditure pattern in hospitals and on the cost of personal health care. In this connection reference was made to the study which had examined the pattern of personal expenditure on drugs for different social classes (cited above). It was also said that the unjustified increase in the consumption of pharmaceuticals had been causing concern to the government, especially because of the emergence of a new pathology of adverse reactions to drugs, which could be attributed at least partly to self-medication. The new legislation was also meant to deal with these 
Table 1

\section{Comparative prices of some national formulary and equivalent proprietary drugs in 1969}

\begin{tabular}{|c|c|c|}
\hline $\begin{array}{l}\text { Phenytoin sodium inj. ( } 100 \mathrm{mg} \text { ) } \\
\text { 'Epamin' }\end{array}$ & $\begin{array}{c}N F \\
\mathrm{E}^{\circ} \\
1.90\end{array}$ & $\begin{array}{c}\text { Proprietary } \\
\mathrm{E}^{\circ}\end{array}$ \\
\hline $\begin{array}{l}\text { Phytomenadione inj. (10 mg) } \\
\text { 'Konakion' }\end{array}$ & 8.50 & 19.69 \\
\hline $\begin{array}{l}\text { Prednisone tabs. ( } 5 \mathrm{mg} \text { ) } \\
\text { 'Meticorten' }\end{array}$ & 4.00 & 13.20 \\
\hline $\begin{array}{l}\text { Dipyrone tabs. ( } 300 \mathrm{mg}) \\
\text { 'Conmel' (324 mg) }\end{array}$ & 2.20 & 6.23 \\
\hline $\begin{array}{l}\text { Sulphamethoxypyridazine tabs. } \\
(500 \mathrm{mg}) \\
\text { 'Lederkyn' }\end{array}$ & 2.60 & 13.80 \\
\hline
\end{tabular}

US $\$ 1=E^{\circ} 13.36$

issues, and in general to help bring about a rationalisation of the use of pharmaceutical products.

These questions were not being taken up effectively at the time by WHO or by its regional organisation in the Americas, the Pan American Health Organisation (PAHO). It was only in the late 1970s that these, and other international organisations, began to show a serious concern for these matters. ${ }^{2}$ At the time PAHO was preoccupied with a scheme to establish a reference laboratory, which would help member countries control the quality of drugs, and it was agreed in 1969 to establish such a laboratory as soon as possible in Montevideo. But this was not the most important issue of the complex of policy problems relating to pharmaceuticals. It would have been more sensible if PAHO had supported the idea of a formulary of generic drugs and promoted it within WHO. This might have brought forward work on the list of essential drugs, which in the event did not see the light of day till almost 10 years later [WHO 1977].

\section{Some Notes on the Allende Period}

During the three years of President Allende's government, pharmaceutical policies remained in

${ }^{2}$ Editors' note: see article by Patel in this issue. their essentials the same as those of the previous period. The production of Laboratorio Chile continued to increase: from $500 \mathrm{mn}$ units in 1970 to $757 \mathrm{mn}$ in 1972. Sixty per cent of the items on the list were by then available in the pharmacies. Nevertheless, progress was slower than had been anticipated for the period 1971 to 1973. The NF Commission was changed, and the pace of making new NF drugs available to the public, and of expanding production, fell off during 1972-73. The health sector was experiencing the widespread turmoil that affected all public services at that time. Fortunately the efficient secretariat of the Commission was left unchanged, and the Commission continued to give advice on the licencing of drugs.

The mass media continued to comment on what was still a novelty; though not uncritical, that comment was on the whole favourable and encouraging. A feature in the Sunday magazine of the country's largest quality news paper (of conservative persuasion) was not atypical:

'While the NF is reducing the prices of the most used drugs, only some doctors prescribe them ...' 'Controversial changes in the health field are being provoked by more than one hundred generics affordable by all ...'

'A public health specialist suggests that health shouldn't be the object of profit ... Of course the NF does not restrict the freedom of doctors in the hospitals: doctors prescribe drugs, not product names ... The ideas that inspired the NF are quite consistent with medical ethics, as they help to give more and better services to the community ...'

'The NF enables people to spend less on drugs, and that must be good for health. The money saved by patients returns to their families in the form of better nutrition, clothing or leisure time, and all of these are related to health ...' [El Mercurio 1972].

\section{Regression under the Military Regime}

In September 1973 the armed forces overthrew the elected government of President Allende. The first Minister of Health of the military government was an outstanding physician and member of the Faculty of Medicine of the University of Chile, who also held high rank in the Air Force. While he remained in office he supported the pharmaceutical policy based on the NF. However, pressures against the NF made their appearance after the first minister was replaced by successive generals and the government imposed its free market policies on the country. The existing regulations were relaxed, and the marketing of new drugs - imported as well as domestically produced - was made easier. The NF Commission itself was abolished in 1975. Since then the updating of the NF has been undertaken by officials in the Ministry of 
Health. It has been reduced to a simple listing of drugs as the descriptive sections on such therapeutic group - so useful for prescribers - have been omitted. The NF now also lacks the scientific standing conferred on it earlier by the professional qualifications of the Commission's members.

With the relaxation of the procedures for introducing new drugs into the market came a loosening of the regulations affecting pharmacies. As a result, pharmacies sprang up like mushrooms in the mid and late $1970 \mathrm{~s}$. The free market illusion suggested that a massive supply would lead to widespread competition and thereby to price reductions. Needless to say, this did not happen: drug prices are not established in the retail market but earlier through the control of production, promotion and distribution. And the failure of Chile's free market policies have not left the pharmacies unaffected: over the past year, bankruptcies have been an almost daily occurrence.

It is no wonder that these policies also affected Laboratorio Chile. By 1975 it was well behind its production schedule, and less than 50 per cent of the products included in the NF were being manufactured. Even so, those products that were made available commercially had price tags that were considerably lower than those of their proprietary equivalents. Not atypical were percentage differences of 45 and 73 per cent between NF ampicillin capsules and the two most widely sold brand name equivalents; for diazepam the differences were 48 and 263 per cent. The price gap for some drugs was much higher: the cheapest proprietary propanolol tablets on the market were 289 per cent more expensive than their NF equivalent and another brand cost over 10 times as much as the generic [Ministério de Salud 1978]. The savings made by the generic drug policy continue to be of the greatest importance to the public health services.

\section{Final Comments}

It is clear that the objectives of the NF have been only partially achieved, and that in some respects there has even been regression. It is not surprising that little collaboration was forthcoming from the pharmaceutical TNCs; but even without such collaboration, a determined national government could have had a very substantial impact. Such determination has not existed in Chile over the last 10 years.

The benefits of a national formulary will be limited as long as production of the drugs on its list is inadequate. Without enough financial support a public sector producer like Laboratorio Chile cannot expand the market for generics, a market that is of little interest to the private companies. Without an authority such as the NF Commission to play an official role in the process of decision-making concerning import, production, marketing and quality control of pharmaceuticals, the public cannot be adequately protected from the anarchy of a free market in drugs. Without a strong professional body which can promote a pattern of prescribing based on low-cost drugs, doctors will be inordinately influenced by the publicity of the pharmaceutical companies. All these condittions are absent in Chile today. To elaborate briefly on only one of these issues: the military government has reduced the power of the Chilean Medical Association as it has done with all such professional bodies - potentially independent centres of power that cannot be tolerated. The participation of the Association in the formulation of the country's health policy is now marginal.

So far, the government has accepted the survival of the NF, though apparently half-heartedly. But the truth is that Laboratorio Chile remains constantly in the government economists' sights. There have been many rumours that the government was about to call for bids so that the enterprise might be transferred to the private sector. So far that has not happened, perhaps in part because those working in it have voiced their objections to this course of action, which would automatically mean the end of the NF as an effective policy instrument.

Since the installation of the military government the country's economic policies have been based on the principles of the free market. The experience of the past 12 months or so, when the Chilean economy spiralled down into a state of near-collapse, shows that even in macroeconomic terms these principles do not work. How much less are they relevant to the market in pharmaceuticals. Economic anarchy in this sector has extremely serious consequences for the health of the population of a developing country such as Chile. 


\section{References}

Business International, 1968, 'Chile's policy on pharmaceutical products', February

Colegio Médico de Chile, 1969, 'Editorial', Vida Médica, July

Diaz, S., 1966, 'El gasto médico familiar', Cuadernos MédicoSociales, vol 8 no 4

El Mercurio, 1972, 'Los ilustres desconocidos', Revista del Domingo, 6 February

Ministério de Salud Pública, Chile, 1966, 'Sesión constitutiva de la Comisión del FN', 22 April, (archives)

-1969, A. Bello (ed), Formulario Nacional de Medicamentos I, Santiago
Ministério de Salud, 1978, Los Medicamentos en Chile

United States, Senate, Select Committee on Small Business, 1968, Competitive Problems in the Drug Industry (Present Status of Competition), hearings before the sub-committee on monopoly, part 5, 'Profits in the drug industry', USGPO, Washington

Valdivieso, R. and B. T. Juricic, 1970, 'El sistema nacional de salud en Chile', Boletín, OPS/PAHO, vol 68 no 6, June, pp 478-85

WHO, 1977, The Selection of Essential Drugs, report of a WHO expert committee, Technical Report Series, 615, Geneva 